\title{
Differentiating cells of murine stratified squamous epithelia constitutively express plasminogen activator inhibitor type 2 (PAI-2)
}

\author{
Accepted: 29 June 1998
}

\begin{abstract}
In stratified squamous epithelia a critical balance among cell proliferation, differentiation, and death must be maintained in order for these tissues to fulfill their barrier function. Previous studies have demonstrated that plasminogen activator inhibitor 2 (PAI-2) is a product of differentiating epidermal keratinocytes, suggesting a role for this inhibitor during squamous differentiation. Furthermore, in certain tumor cell lines, overexpression of PAI-2 confers resistance to the induction of programmed cell death, suggesting cytoprotective function(s). In the present study we demonstrate that PAI-2 mRNA and protein are constitutively and uniquely expressed in differentiating cells of murine stratified squamous epithelia, including epidermis, esophagus, vagina, oral mucosa, and tongue. PAI-2 immunohistochemical localization patterns suggest a predominantly cytosolic distribution, consistent with biochemical identification of the major PAI-2 species as a $43-\mathrm{kDa}$, presumably non-glycosylated protein. Functional analysis shows that the majority of epithelial PAI-2 is active. In contrast to the high levels of PAI-2 expression in stratified squamous epithelia, little or no PAI-2 is detectable in simple epithelia. These findings suggest that epithelial PAI-2 may mediate inhibition of intracellular proteinases associated with events during terminal differentiation and death that are unique to stratified squamous epithelia.
\end{abstract}

B.C. Risse · H. Brown · R.M. Lavker · P.J. Jensen (

Department of Dermatology, University of Pennsylvania,

242 CRB, 415 Curie Boulevard, Philadelphia, PA 19104-6142, USA

Tel.: +1-215-8980174, Fax: +1-215-5732143

e-mail: jensenp@mail.med.upenn.edu

J.M. Pearson · D. Ginsburg

Howard Hughes Medical Institute,

University of Michigan Medical Center, Ann Arbor, MI, USA

M.S. Baker

Department of Biological Sciences, University of Wollongong, Australia

\section{Introduction}

Stratified squamous epithelia are self-renewing tissues consisting of multiple layers of keratinocytes that line body surfaces and are designed to protect the organism from physical, chemical or microbial perturbations. To fulfill their vital barrier function, stratified squamous epithelia must maintain a dynamic balance among proliferation, terminal differentiation, and death. The proliferative keratinocyte population is located primarily in the basal layer residing along the basement membrane; the superficial layers are comprised of postmitotic, increasingly differentiated cells. Terminal differentiation culminates with the death of the keratinocyte and its conversion into a keratin filament-matrix complex encased by a thickened proteinaceous membrane formed via the crosslinking action of transglutaminase. These terminally differentiated cells, which are continuously shed from the epithelial surface, constitute a central aspect of the protective function of stratified squamous epithelia (Green 1977, 1980; Eckert and Rorke 1989).

Terminal differentiation in stratified squamous epithelia may be thought of as a high specialized form of programmed cell death, in which the postmitotic keratinocyte must follow an elaborate series of changes in gene and protein expression prior to nuclear disintegration, protein cross-linking, and death (Fesus et al. 1991; Gavrieli et al. 1992; Polakowska and Haake 1994; Tamada et al. 1994; Metcalfe and Streuli 1997). Intracellular proteinases have been implicated both in programmed cell death and terminal differentiation. An increasingly large family of intracellular proteinases promotes programmed cell death through cleavage of cytoplasmic and/or nuclear targets (Ashkenas and Werb 1996). Furthermore, numerous proteins are degraded during the conversion of a keratinocyte to a terminally differentiated, dead cell; thus proteolytic enzymes must be active during the last stages of differentiation (Green 1977, 1980; Eckert and Rorke 1989; Resing et al. 1993). Numerous proteinase inhibitors have evolved which regulate proteinases and thus may prevent damage to cells 
and tissues. One such proteinase inhibitor, which we have previously suggested may be involved in the regulation of keratinocyte differentiation, is plasminogen activator inhibitor type 2 (PAI-2; Lyons-Giordano et al. 1994; Jensen et al. 1995; Wang and Jensen 1998). A recent survey of mouse organs revealed that the highest level of this inhibitor is in epidermal keratinocytes (Kawata et al. 1996), consistent with the observations that PAI-2 mRNA, antigen, and activity are readily detectable in human epidermis in vivo (Hibino et al. 1988; LyonsGiordano et al. 1994).

As a type of serine proteinase inhibitor (serpin), PAI-2 is unusual in that it lacks a hydrophobic signal sequence and thus a significant fraction is retained within the cytoplasm (Ye et al. 1988; Belin et al. 1989). PAI-2 is found in two forms, non-glycosylated and glycosylated. In macrophages, the latter is found in the conditioned medium (Wohlwend et al. 1987a, b) but in cultured human keratinocytes both forms remain cell associated (Wang and Jensen 1998). Only very few other proteins (e.g., yeast invertase, mammalian gelsolin) have been found simultaneously in cytoplasmic and secreted forms (Belin et al. 1989). The simultaneous presence of cytosolic and secreted PAI-2 suggests potentially distinct functions of the two forms.

As reflected by its name, the only known proteolytic enzyme targets for PAI-2 are urokinase-type plasminogen activator (uPA) and tissue-type plasminogen activator (tPA) (Andreasen et al. 1990; Kruithof et al. 1995). Both PAs convert plasminogen to its active form, plasmin, which acts in the extracellular space to cleave a number of substrates, including fibrin, other extracellular matrix molecules, and procollagenase (Danø et al. 1985). There is good evidence to support the involvement of the PA cascade in numerous physiological and pathological processes, e.g., vascular patency, cell migration, inflammation, neuronal degeneration, and tumor invasion (Carmeliet and Collen 1995; Rømer et al. 1996; Andreasen et al. 1997; Tsirka et al. 1997). Although most of the actions of uPA and tPA are mediated via cleavage of plasminogen, other substrates have been proposed (e.g., hepatocyte growth factor, fibronectin; Quigley et al. 1987; Naldini et al. 1992; Mars et al. 1993); however, consistent with the fact that the PAs are secreted enzymes, their proposed substrates are all extracellular. The secreted form of PAI-2 is likely to regulate PA activity, particularly uPA, which it inhibits more efficiently than tPA (Andreasen et al. 1990). However, given that a substantial fraction of PAI-2 remains in the cytosol of cells synthesizing this inhibitor, the possibility of a plasminogen activator-independent, intracellular role appears reasonable. Several studies have indeed provided evidence for this point of view. Overexpression of PAI-2 in the cytoplasm of fibrosarcoma or epithelial cell lines has been shown to confer resistance to the induction of programmed cell death (Kumar and Baglioni 1991; Dickinson 1995). Active intracellular PAI-2 was required for this function, but its inhibitory activity was not directed against uPA (Dickinson et al. 1995, 1998). These data have led to the hypothesis that PAI-2 may exert cytoprotective functions, independent of UPA inhibition, in a variety of cell types.

We have previously postulated that such a cytoprotective function of PAI-2 may extend to normal epidermis. In human epidermis, PAI-2 mRNA and protein have been localized predominantly to superficial layers (Hibino et al. 1988; Lyons-Giordano et al. 1994), indicating that PAI-2 is a product of differentiated keratinocytes. Consistent with these in vivo data, more differentiated keratinocyte cultures have relatively greater levels of PAI-2 (Wang and Jensen 1998). Thus PAI-2 is appropriately placed to protect differentiating epidermal keratinocytes from premature action of cytoplasmic proteinases that may contribute to their terminal differentiation, dissolution, and eventual death. To consider this hypothesis further, we have characterized PAI-2 using biochemical, immunohistochemical, and/or in situ hybridization approaches in a variety of murine epithelia. We reasoned that determination and comparison of PAI-2 expression patterns and properties within different types of epithelia would suggest the physiological circumstances under which PAI-2 normally functions. Our data indicate that PAI-2 is uniquely expressed by stratified squamous epithelia, in which its properties are consistent with a protective role during terminal differentiation.

\section{Materials and methods}

Mice

For immunohistochemical staining and in situ hybridization, skin biopsies were collected from C57BL/6, C57BL/6 - 129 hybrid, and Sencar strains at different ages of life. Our results showed no strain-related differences in PAI-2 expression patterns. Biochemical and functional analysis of epidermal extracts were conducted using C57BL/6 mice. Mice were euthanized in $\mathrm{CO}_{2}$.

\section{Tissue preparation}

Skin biopsies were collected from the nape of the neck unless specified otherwise. Tissues for immunohistochemical staining and in situ hybridization were fixed overnight in $4 \%$ paraformaldehyde/Dulbecco's phosphate-buffered saline (PBS; Life Technologies, Grand Island, N.Y., USA), incubated in $80 \%$ ethanol for 24 $\mathrm{h}$, and paraffin embedded. Sections $(5 \mu \mathrm{m})$ were prepared on $\mathrm{Su}-$ perfrost Plus glass slides (Fisher Scientific, Pittsburg, PA., USA).

\section{Immunohistochemical staining}

Polyclonal antiserum against mouse PAI-2 was prepared in rabbit by injection with a mouse PAI-2:GST fusion protein that had been purified from inclusion bodies by 8-M urea extraction and glutathione-Sepharose chromatography. The antiserum was adsorbed with sham-transfected bacterial lysates to remove any cross-reactivity with either bacterial or GST antigens. Rabbit anti-mouse PAI-2 IgG was purified using an ImmunoPure (A) IgG Purification kit (Pierce, Rockford, IL., USA). Immunohistochemical staining was performed using a Vectastain $\mathrm{ABC}$ (avidin-biotin-peroxidase complex) kit (Vector Laboratories, Burlingame, CA., USA). Paraffin sections were briefly heated to $55^{\circ} \mathrm{C}$, deparaffinized in xylene for $3 \times 5 \mathrm{~min}$, rehydrated through a graded ethanol series, and fixed in $4 \%$ paraformaldehyde/PBS. After rinsing in PBS, 
non-specific binding was blocked in $10 \%$ normal goat serum in PBS. Sections were incubated with rabbit anti-mouse PAI-2 IgG $(5 \mu \mathrm{g} / \mathrm{ml})$ overnight at $4^{\circ} \mathrm{C}$. Sections were washed $3 \times 10 \mathrm{~min}$ in PBS, then incubated with biotinylated goat anti-rabbit IgG (7.5 $\mu \mathrm{g} / \mathrm{ml}) 1 \mathrm{~h}$ at room temperature. Following washes in PBS, sections were incubated with the avidin-biotin-peroxidase complex according to the manufacturer's recommendation. Detection of antibody binding was conducted using the substrate 3,3'-diaminobenzidine (Sigma, St. Louis, MO., USA). Control experiments were performed using normal rabbit IgG.

\section{In situ hybridization}

In situ hybridization for mouse PAI-2 mRNA was performed according to procedures published previously (Keeton et al. 1993; Jensen and Lavker 1996). A 930-bp PstI-PvuII fragment of the mouse PAI-2 cDNA (kindly provided by D. Belin) was subcloned into pBluescript SK+/- (Stratagene, La Jolla, CA., USA) at the EcoRI-HindIII site. Digestion with HindIII and transcription with T3 RNA polymerase were used for antisense probes, and digestion with SmaI and transcription with T7 RNA polymerase were used for sense probes. [ $\left.{ }^{35} \mathrm{~S}\right]$-labeled RNA probes were transcribed using a Riboprobe RNA Labelling kit (Promega Corporation, Madison, WI., USA).

\section{Epidermal extraction}

The entire trunk skin was removed and immersed in $0.15 \mathrm{M} \mathrm{NaC}$ for $1 \mathrm{~min}$ at $56^{\circ} \mathrm{C}$ to separate the epidermis from the underlying dermis. Epidermis was homogenized on ice in $0.01 \mathrm{M}$ sodium phosphate $\mathrm{pH} 7.0$ (ca. $10 \mu \mathrm{l}$ per $\mathrm{mg}$ wet weight) and extracted for $30 \mathrm{~min}$ at $4^{\circ} \mathrm{C}$. After centrifugation (ca. $7000 \mathrm{xg}$ for $10 \mathrm{~min}$ ), the supernatant (low-salt extract) was collected. The remaining pellet was then resuspended in an equal volume of $2 \mathrm{M} \mathrm{KSCN/0.1 \%} \mathrm{Tri-}$ ton $\mathrm{X}-100$ and reextracted for $30 \mathrm{~min}$ at $4^{\circ} \mathrm{C}$ followed by centrifugation. Supernatant (high-salt extract) was collected and dialyzed against $0.01 \mathrm{M}$ sodium phosphate, $\mathrm{pH}$ 7.0. All samples were stored at $-70^{\circ} \mathrm{C}$. Using this extraction procedure, PA inhibitors can be detected in the low-salt extract whereas PA enzymes are present in the high-salt extract, as we previously found for human epidermis (Lyons-Giordano et al. 1994). Determination of total extracted protein was performed using a BCA Protein Assay kit (Pierce).

\section{Western blot}

Samples were electrophoresed in a $9.5 \%$ polyacrylamide gel in the presence of SDS prior to electroblot transfer onto PVDF membrane (Immobilon P; Millipore, Bedford, MA., USA). Non-specific antibody binding was blocked in $1 \%$ bovine serum albumin (Catalog number A-4378, Sigma) in TRIS-buffered saline (TBS; $20 \mathrm{mM}$ TRIS base, $137 \mathrm{mM} \mathrm{NaCl}, \mathrm{pH} \mathrm{7.6)}$ containing $0.2 \%$ Tween-20. Immunodetection was conducted by incubation with rabbit anti-mouse PAI-2 $\operatorname{IgG}(1.5 \mu \mathrm{g} / \mathrm{ml})$ for $1 \mathrm{~h}$ at room temperature. Blots were washed in TBS/1\% Tween-20 and incubated with horseradish peroxidase-labelled goat anti-rabbit IgG (1:1000 dilution: Boehringer Mannheim Biochemicals, Indianapolis, IN., USA) for $1 \mathrm{~h}$ at room temperature. Following washes in TBS/1\% Tween-20, antibody binding was detected using an ECL kit (Amersham Life Science, Arlington Heights, IL., USA). Control experiments were performed using normal rabbit IgG.

Functional activity of epidermal PAI-2 was assessed by preincubation prior to electrophoresis of epidermal extracts $(15 \mu \mathrm{g}$ total protein) with $50 \mathrm{ng} 33-\mathrm{kDa}$ human uPA (Mochida Pharmaceuticals, Tokyo, Japan) for $10 \mathrm{~min}$ on ice.

\section{$\mathrm{uPa}$ inhibitory assay immunoprecipitation}

PA inhibitory activity was assessed using a kinetic assay which measures the inhibition of uPA-mediated cleavage of the chromo- genic substrate S-2444 (Chromogenix, Mölndal, Sweden). All assays were performed in 96-well plates in a final volume of $110 \mu \mathrm{l}$. Epidermal extracts were incubated in the presence of standard uPA (25 Plough U/ml; Leo Pharmaceutical Products, Ballerup, Denmark), $1 \mathrm{~h}$ at room temperature, to allow formation of uPA:PA inhibitor complexes. The optical density at $405 \mathrm{~nm}\left(\mathrm{OD}_{405}\right)$ was measured prior to substrate addition, and then with time after addition of $0.3 \mathrm{mM} \mathrm{S}-2444$. $\mathrm{OD}_{405}$ readings were normalized by subtraction of background readings and compared to a standard curve obtained with 25 Plough $\mathrm{U} / \mathrm{ml}$ standard uPA alone.

In some experiments, prior to the inhibitory assay, PAI-2 was immunoprecipitated from epidermal extracts using rabbit antimouse PAI-2 IgG (see above) or rabbit anti-mouse PAI-1 IgG (kindly donated by D. Loskutoff). Protein G Plus/protein A - agarose beads (Oncogene Reseach, Cambridge, MA., USA) were pretreated by washes in NET buffer $(0.5 \mathrm{M} \mathrm{NaCl}, 1 \mathrm{mM}$ EDTA, 50 $\mathrm{mM}$ TRIS-HCl, $\mathrm{pH} 8.1$ ) containing $0.5 \%$ and then $0.05 \%$ Nonidet P-40 (NP-40; Sigma). To reduce non-specific binding, beads were incubated in $0.2 \%$ hemoglobin in NET/0.05\% NP-40, $1 \mathrm{~h}$ at $4^{\circ} \mathrm{C}$, and in $2 \%$ immunoglobulin-free BSA (Sigma) in NET/0.05\% NP40 , overnight at $4^{\circ} \mathrm{C}$. For immunoprecipitation, low-salt epidermal extracts $(50 \mu \mathrm{l}$ containing ca $85 \mu \mathrm{g}$ total extracted protein) were incubated with $100 \mu \mathrm{l}$ Protein G Plus/protein A - agarose beads and $20 \mu \mathrm{g}$ rabbit anti-mouse PAI-2 IgG overnight at $4^{\circ} \mathrm{C}$. Control experiments were performed by addition of normal rabbit IgG or by omitting additions of antibody and beads. Agarose beads were pelleted and supernatants were assayed for uPA inhibitory activity as described above.

\section{Results}

The pattern of PAI-2 expression changes during murine epidermal development

During the first 2 weeks of life, mouse epidermis undergoes characteristic morphological changes. Late gestational and neonatal mouse epidermis can be considered in a 'hyperproliferative' state with approximately seven or eight layers of nucleated keratinocytes: one layer of basal keratinocytes (the proliferative layer), one or two layers of suprabasal cells, one or two layers of spinous cells, and two or three layers of granular cells beneath the enucleated cells of the cornified layers. Keratinocytes of the suprabasal, spinous, and granular layers constitute the differentiating population of epidermal cells. By approximately 2 weeks of life, epidermal proliferation has declined and the epidermis has become much thinner, consisting of the basal layer, one layer of suprabasal cells, and several enucleated cornified layers, similar to the adult. We investigated the expression of PAI-2 antigen and mRNA in mouse epidermis during the different stages of epidermal development using immunohistochemical staining and in situ hybridization, respectively.

In late gestational (Fig. 1A) and early neonatal (Fig. 1C) mouse skin, we detected strong staining for PAI-2 antigen in most suprabasal epidermal layers, but the lowermost two or three epidermal layers did not contain detectable PAI-2 antigen. During the first several days of life, as the epidermis gradually thinned, PAI-2 antigen became apparent in most of the epidermis, but the basal cells were still spared (Fig. 1C). By 2 weeks of age, the entire epidermis, including the basal cells, showed very intense staining for PAI-2, a pattern which was main- 


\section{Fetal}
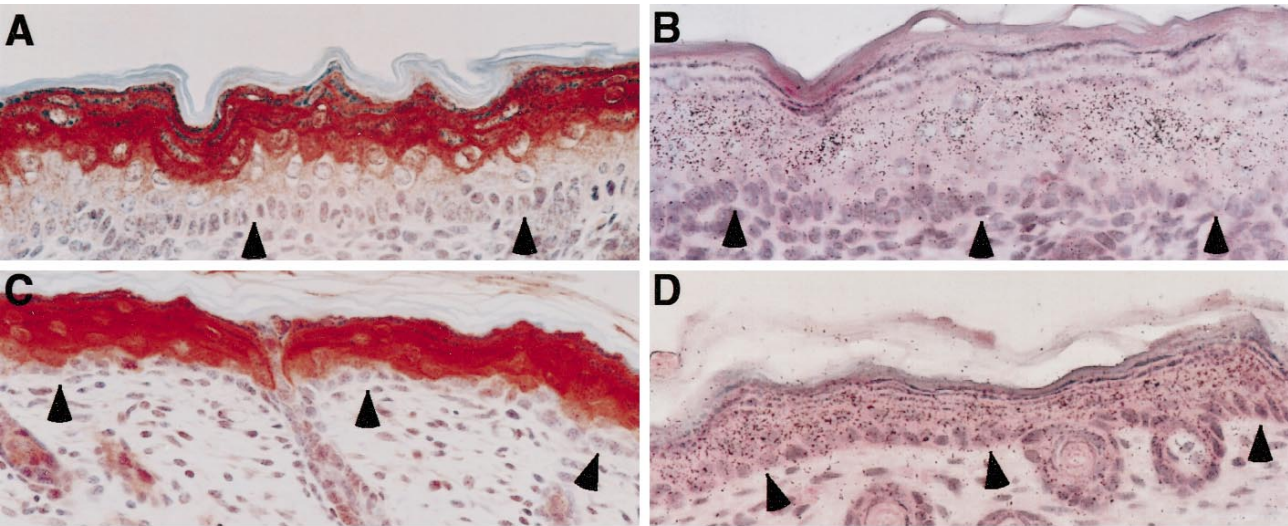

Neonatal

Adult
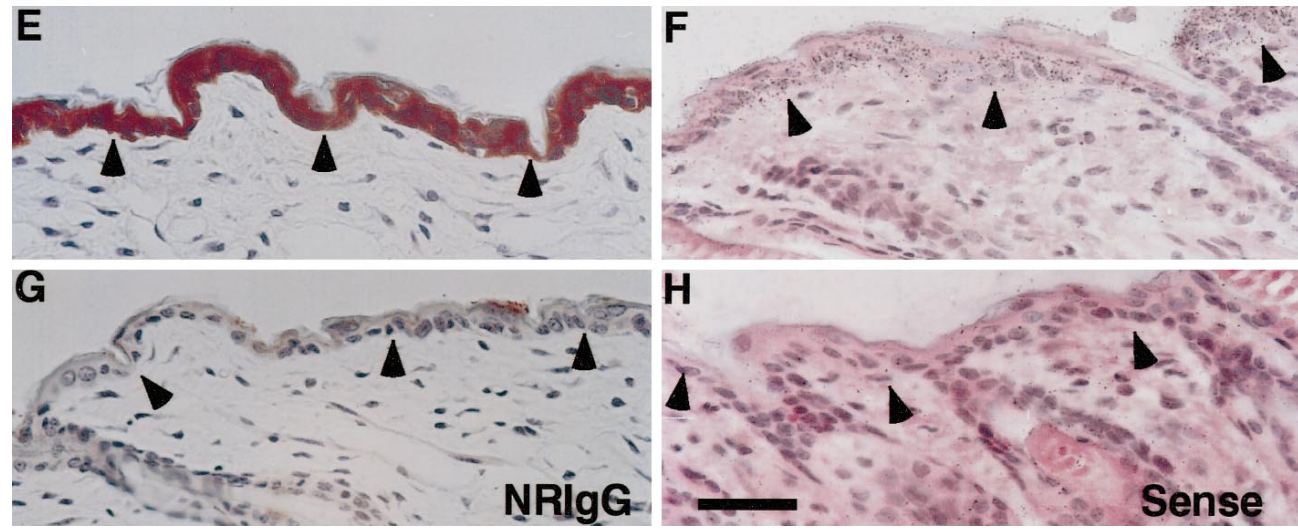

Fig. 1A-H Plasminogen activator inhibitor type 2 (PAI-2) expression patterns change during murine epidermal development. PAI-2 antigen $(\mathbf{A}, \mathbf{C}, \mathbf{E})$ and mRNA $(\mathbf{B}, \mathbf{D}, \mathbf{F})$ were localized in mouse epidermis at day 18 of gestation $(\mathbf{A}, \mathbf{B})$, day 5 of life $(\mathbf{C}, \mathbf{D})$ and day 20 of life $(\mathbf{E}, \mathbf{F})$. Immunohistochemical staining was performed using polyclonal rabbit anti-mouse PAI-2 IgG, biotinylated secondary $\operatorname{IgG}$, the avidin-biotin-peroxidase complex, and the substrate 3,3'-diaminobenzidine. In situ hybridization was performed using $\left[{ }^{35} \mathrm{~S}\right]$-labeled RNA probe specific for mouse PAI-2. In control experiments, adult mouse epidermis was incubated with normal, non-immune rabbit $\operatorname{IgG}(\mathbf{G} N R I g G)$ or $\left[{ }^{35} \mathrm{~S}\right]$-labeled sense probe for PAI-2 mRNA (H). Arrowheads mark the dermal-epidermal junction. PAI-2 antigen and mRNA were expressed in suprabasal, differentiating keratinocytes of fetal and neonatal epidermis (A-D). At these ages, basal keratinocytes showed no specific staining for PAI-2 antigen, and little or no signal for PAI-2 mRNA. In thin, adult mouse epidermis, PAI-2 antigen and mRNA were consistently found both in suprabasal and basal keratinocytes (E F). The cornified layer showed no consistent staining for PAI-2, which may be due either to degradation of PAI-2 or to masking of antigenic determinants upon cross-linking. Bar $40 \mu \mathrm{m}$

tained throughout adulthood (Fig. 1E). At all times, PAI-2 staining was diffuse and cytoplasmic, indicative of an intracellular localization. In situ hybridization revealed expression patterns for PAI-2 mRNA that were concordant with the PAI-2 immunohistochemistry. In late gestational epidermis, the signal for PAI-2 mRNA was detected exclusively in suprabasal and spinous keratinocytes (Fig. 1B). Similarly, in neonatal epidermis, most PAI2 mRNA was found in immediately suprabasal and spinous layers, although a few basal cells also contained signal (Fig. 1D). Adult epidermis showed weaker expression of PAI-2 mRNA, but signal was present in all layers of the epidermis (Fig. 1F). These results demonstrate that differentiating epidermal keratinocytes constitutively express PAI-2; in contrast, basal keratinocytes only express PAI-2 when the epidermis approaches its adult morphology, i.e., relatively thin with a low resting proliferative rate.

The majority of epidermal PAI-2 is present in its $43 \mathrm{kDa}$, non-glycosylated form

Via western blot analysis, we determined that PAI-2 was recovered in the low-salt extract of murine epidermis, but was not detectable in the high-salt/detergent fraction. These data indicate that epidermal PAI-2 is located mostly in the soluble fraction of cellular proteins. The major band of epidermal PAI-2 had an apparent molecular weight of $43 \mathrm{kDa}$ (Fig. 2), consistent with previously published sizes for endogenous (Wohlwend et al. 1987a) and recombinant (Kawata et al. 1996) non-glycosylated mouse PAI-2. Interestingly, when lanes were standardized to equivalent amounts of total protein, this $43 \mathrm{kDa}$ PAI-2 showed an increase in signal intensity in adult compared to neonatal extracts (Fig. 2A). Neonatal epidermal extracts contained a second band at $105 \mathrm{kDa}$. Several other bands for PAI-2 were detectable when maximal volumes of low-salt extracts were loaded (Fig. 2B). The specificity of these bands was verified by control immunoblot analysis with normal, non-immune rabbit IgG (data not shown). Given that uPA and tPA activity are detectable in extracts of fetal and neonatal mouse 


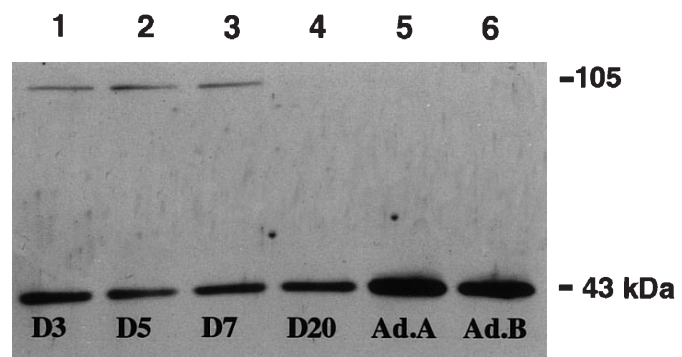

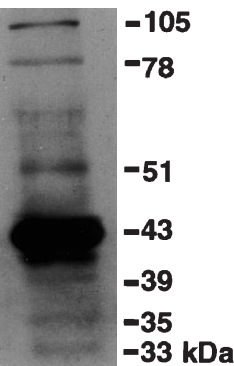

Ad.
Fig. 2A, B The majority of epidermal PAI-2 is present in a $43 \mathrm{kDa}$, non-glycosylated form. Low-salt epidermal extracts were separated by reducing SDS-PAGE and subjected to western blot analysis using rabbit anti-mouse PAI-2 IgG, goat anti-rabbit IgG-horseradish peroxidase, and chemiluminescent detection. A Western blot analysis of epidermal extracts from mice at days 3,5 , 7, 20 of life and two adults (older than 6 months). All lanes were loaded with $14 \mu \mathrm{g}$ total cellular protein. Under reducing conditions, the majority of epidermal PAI-2 was detected as a single 43 $\mathrm{kDa}$ band. The relative amount of this $43 \mathrm{kDa}$ band was increased in adult compared to neonatal or adolescent epidermis. A second band $(105 \mathrm{kDa})$ was present in neonatal epidermal extracts. B The maximal volume (containing $50 \mu \mathrm{g}$ ) total protein of an adult epidermal extract was loaded. Additional bands for PAI-2 were detectable at $105,78,51,39,35$, and $33 \mathrm{kDa}$. The specificity of these bands was demonstrated by immunoblotting with normal rabbit IgG (data not shown). These additional bands may represent complexed, glycosylated, and/or cleaved forms of PAI-2

epidermis (Jensen and Lavker 1996), we postulate that these bands may represent complexes of PAI-2 with uPA or tPA. Such complexes are known to be resistant to SDS and reducing agents (Wohlwend et al. 1987b). The molecular size of such complexes would be expected within a

Fig. 3A, B The majority of epidermal PAI-2 is functionally active and forms SDS-stable complexes with urokinase-type plasminogen activator (uPA). Adult ( $>6$ months of age) and neonatal ( $D 4$ day 4 of life) low-salt epidermal extracts were incubated in the absence or presence of the $33 \mathrm{kDa}$ form of human uPA prior to SDS-PAGE. Western blot analysis was performed using 9.5\% SDS-polyacrylamide gels and immunodetection with rabbit anti-mouse $\mathrm{IgG}$, as described for Fig. 2. Under non-reducing conditions (A), control extracts of adult and neonatal mouse epidermis contained a doublet for PAI-2 at $45-43 \mathrm{kDa}$, which was converted to a band at $76 \mathrm{kDa}$ upon incubation with uPA. Under reducing conditions $(\mathbf{B})$, there was a single band detectable for free PAI-2, which complexes with uPA range of approximately $80-110 \mathrm{kDa}$. The intensity of the $105 \mathrm{kDa}$ band was decreased in adult compared to neonatal epidermal extracts (Fig. 2A), consistent with the finding that PA enzyme activity declined considerably after birth, to barely detectable levels in adult epidermis (Jensen and Lavker 1996). We also detected PAI-2 bands at $51,39,35$, and $33 \mathrm{kDa}$. The $51 \mathrm{kDa}$ band is consistent with the published molecular weight for glycosylated forms of human or mouse PAI-2 (Wohlwend et al. 1987a, b; Mikus et al. 1993; Kruithof et al. 1995). The low molecular weight species of 39,35 , and $33 \mathrm{kDa}$ may represent partially degraded and/or cleaved forms of PAI-2. Under non-reducing conditions (Fig. 3A), the major PAI2 band is a doublet of $43-45 \mathrm{kDa}$, probably related to slightly different conformations of the inhibitor.

The majority of epidermal PAI-2 is functionally active and forms SDS-stable complexes with uPA

Since PAI-2, like other serpins, forms SDS-stable complexes with its target proteinases (Wohlwend et al. 1987b) the presence of active inhibitor can be demonstrated by a shift in apparent molecular size on SDSpolyacrylamide gels consequent to incubation with uPA. In order to assess the functional activity of epidermal PAI2 , we incubated low-salt extracts of mouse epidermis with the low molecular weight $(33 \mathrm{kDa})$ form of human uPA (LMW-uPA) and analyzed the samples by western blotting. As shown in Fig. 3, most of the 43-45 kDa PAI2 band was lost upon incubation with uPA and a $76 \mathrm{kDa}$ complex band was formed, in good agreement with the anticipated size for the PAI-2: LMW-uPA complex.
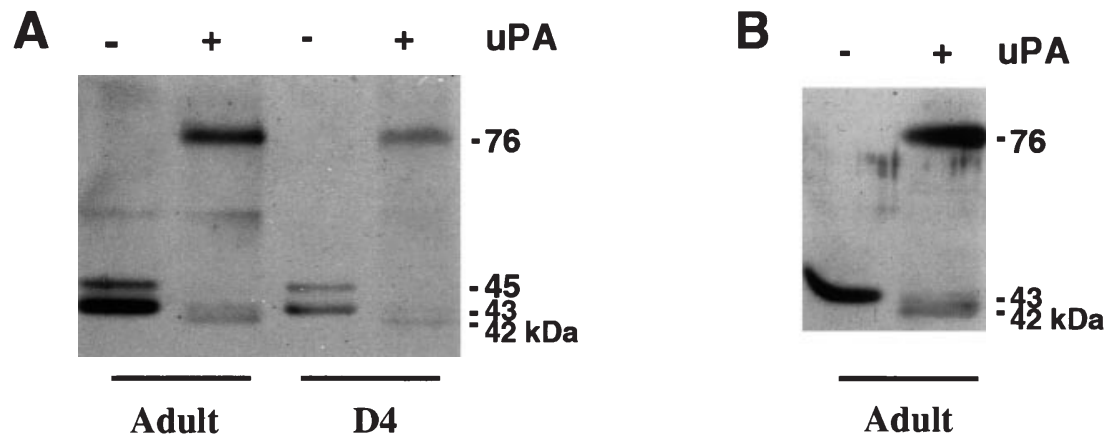

Adult 
A

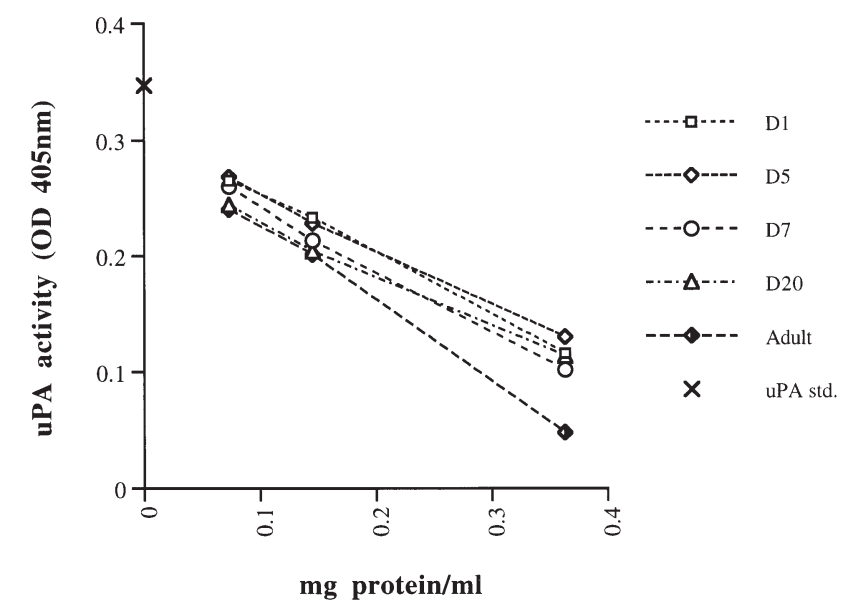

B

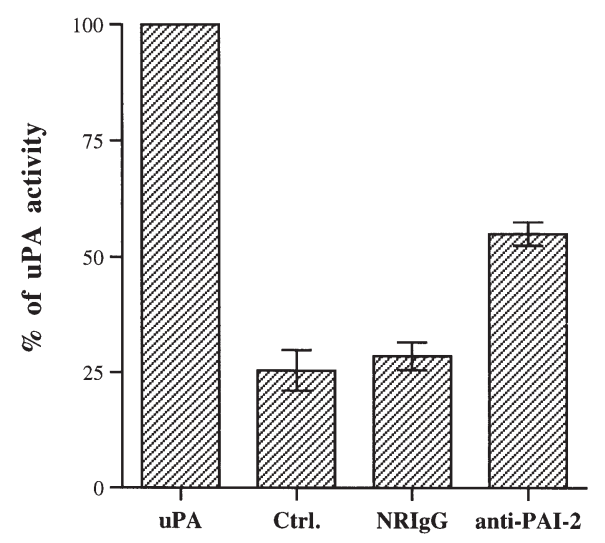

Fig. 4A, B Epidermal PA inhibitory activity is mediated at least partially by PAI-2. A Low-salt extracts of mouse epidermis were adjusted to the indicated concentrations of total protein and incubated with standard uPA ( 25 Plough $\mathrm{U} / \mathrm{ml}$ ) for $1 \mathrm{~h}$ at room temperature to allow PAI:uPA complex formation. The chromogenic uPA substrate S-2444 was then added and uPA activity was assessed by measuring the increase in optical density at $405 \mathrm{~nm}(O D 405 \mathrm{~nm})$ with time. Values shown were obtained after $60 \mathrm{~min}$ of incubation with substrate, a time that was always in the linear range of absorption. Control wells contained only standard uPA at the same concentration ( $u f A$ std.). The presence of uPA inhibitors in the extracts is demonstrated by loss of uPA activity. Epidermal extracts from mice at day $(D)$ 1, 5, 7, 20 of life and from adult mice had similar levels of inhibitory activity. B Low-salt extracts of mouse epidermis were immunoprecipitated with rabbit anti-mouse PAI-2 IgG or, as a control, with normal rabbit $\operatorname{IgG}(N R I g G)$ prior to the inhibitory activity assay described in $\mathbf{A}$. The bar labeled Ctrl. shows data of extracts that were incubated similarly but without addition of antibody. Immunoprecipitation of PAI-2 led to loss of PA inhibitory activity, as indicated by an increase in uPA activity. Data shown represent the average \pm standard deviation of a total of four experiments with epidermal extracts from mice at day 2,4 , or 20 of life)

Thus, the $43 \mathrm{kDa}$ band represents active inhibitor. In addition to the appearance of a complex band after incubation with uPA, we also detected a very faint doublet of $42-43 \mathrm{kDa}$, slightly smaller than the doublet of control extracts. This slightly smaller doublet may suggest the presence of a small amount of inactive PAI- 2 and/or a cleaved fraction of total PAI-2.

Epidermal PA inhibitory activity

is mediated at least partially by PAI-2

To quantify epidermal PAI-2 activity at different developmental stages, we titrated the ability of low-salt epidermal extracts to inhibit uPA-mediated cleavage of the chromogenic substrate S-2444. Incubation of standard uPA with epidermal low-salt extracts led to a concentration-dependent decrease in uPA activity, indicative of the presence of PA inhibitor(s). When low-salt extracts were standardized to equal amounts of total protein (Fig. 4A), indistinguishable levels of PA inhibitory activity were found for adult and neonatal epidermis. To determine whether this inhibitory activity was mediated by PAI-2, we performed immunoprecipitation experiments. Immunoprecipitation with anti-PAI-2 IgG reduced PA inhibitory activity by approximately $40 \%$, demonstrating that a significant part of epidermal PA inhibitory activity was contributed by PAI-2 (Fig. 4B). Increasing the amount of IgG used for immunoprecipitation or subjecting the same sample to repeated immunoprecipitations did not result in further loss of PA inhibitory activity (data not shown), suggesting that immunoprecipitation was complete. Consistent with this interpretation, western blot analysis of low-salt epidermal extracts which were immunoprecipitated with anti-mouse PAI-2 revealed no remaining PAI-2 (data not shown). These data are consistent with the western blots of Fig. 3 in showing active PAI-2 in epidermal extracts. Our inability to remove completely uPA inhibitory activity by immunoprecipitation with anti-PAI-2 antibody may suggest the presence of additional PA inhibitor(s) other than PAI-2. Immunoprecipitation with anti-mouse PAI-1 did not affect PA inhibitory activity in low-salt epidermal extracts.

PAI-2 is expressed solely in suprabasal epidermal keratinocytes of the adult mouse footpad

The thickness of trunk epidermis in the mouse greatly decreases during neonatal life; however, this is not true for all epidermal regions of the body. For example, the epidermis of the footpad remains a thick, multi-layered epithelium throughout the life of a mouse. To address whether adult mouse epidermis invariably expresses PAI-2 both in suprabasal and basal keratinocytes, or whether this expression pattern is exclusive to the thin phenotype of adult mouse epidermis, we localized PAI-2 in footpad epidermis. Similarly to our results in fetal and neonatal mouse epidermis, we found intense staining for PAI-2 in suprabasal epidermal layers of the adult mouse footpad, but no detectable staining in the basal keratinocytes (Fig. 5A). Accordingly, in situ hybridization revealed signal for PAI-2 mRNA in the immediately suprabasal and spinous layers of the footpad but not in the basal keratinocytes or 

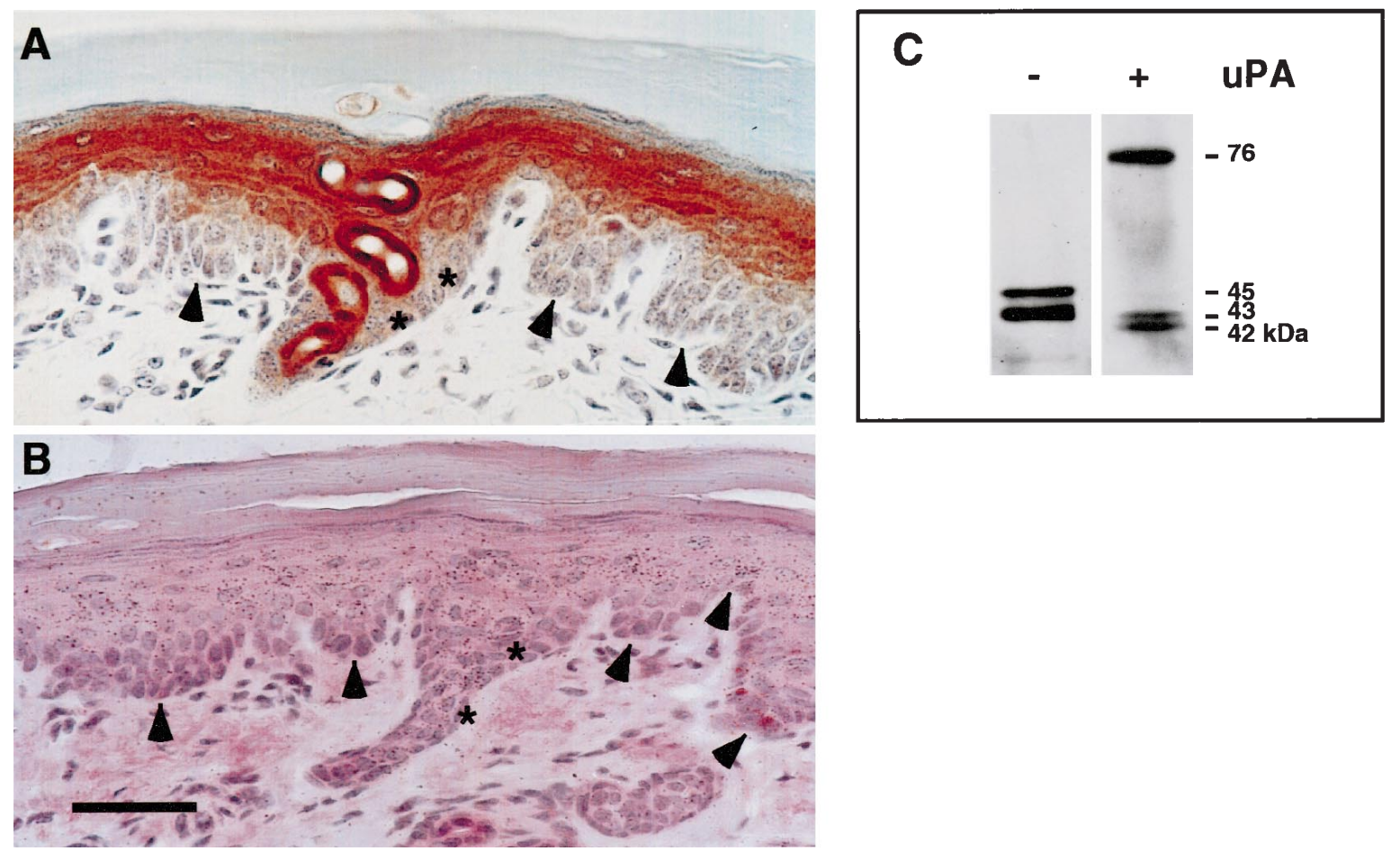

Fig. 5A-C PAI-2 is expressed solely in suprabasal epidermal keratinocytes of the adult mouse footpad. A Immunohistochemical staining of adult mouse footpad epidermis. Suprabasal, differentiating keratinocytes of the stratified adult footpad epidermis displayed strong staining for PAI-2. B In situ hybridization for PAI-2 mRNA of adult mouse footpad epidermis. PAI-2 mRNA is expressed in suprabasal keratinocytes of the immediately suprabasal and spinous layers. Arrowheads mark the dermal-epidermal junction. Cross-section of the duct of a sweat land (asterisks); note the intense staining for PAI-2 in the luminal, ductal epithelial cells. C Western blot analysis of low-salt epidermal extracts of the adult foodpad with and without incubation with the $33 \mathrm{kDa}$ human uPA, as described for Fig. 2. Similarly to extracts of adult trunk epidermis (Fig. 2), control extracts revealed the presence of the 45-43 $\mathrm{kDa}$ PAI-2 doublet. Incubation with uPA led to a size shift of the major PAI-2 band to $76 \mathrm{kDa}$, demonstrating formation of a complex. A faint 43-42 kDa doublet was also detectable after incubation with uPA. Bar $30 \mu \mathrm{m}$

granular cells. The adjacent thin epidermis of the dorsal foot surface was indistinguishable from trunk epidermis with respect to morphology and PAI-2 expression in both basal and suprabasal keratinocytes. Western blot analysis of low-salt extracts of footpad epidermis demonstrated the presence of the typical PAI-2 doublet at $45-43 \mathrm{kDa}$ under non-reducing conditions (Fig. 5B). This band underwent the characteristic size shift to $76 \mathrm{kDa}$ following incubation with LMW-uPA, indicating that PAI-2 of the mouse footpad epidermis is functionally active.

PAI-2 is expressed in suprabasal epithelial cells of stratified squamous epithelia

To determine whether PAI-2 expression is selective for epidermis, we examined PAI-2 in a number of other murine epithelial tissues, including stratified squamous epi- thelia (tongue, oral mucosa, vagina, and esophageal mucosa) and simple epithelia (mucosae of the trachea and small and large intestine). In the mucosa of the adult tongue (data not shown), oral cavity, esophagus, and vagina (Fig. 6), we found PAI-2 antigen and mRNA predominantly expressed in suprabasal, differentiating epithelial cells of the spinous and granular layers, resembling the PAI-2 expression pattern in trunk epidermis of neonatal mice or in the adult footpad epidermis. Basal epithelial cells did not consistently express PAI-2 mRNA or antigen, although in esophageal mucosa, focal regions of basal cells occasionally showed weak expression of PAI-2 (Fig. 6C, D). The simple epithelia of the small and large intestine did not show specific expression of PAI-2 antigen or mRNA (data not shown). The pseudostratified, simple epithelium of the tracheal mucosa showed faint staining for PAI-2 antigen (Fig. 6I, J), but signal for PAI-2 mRNA was not detectable (data not shown). Thus, PAI-2 mRNA was detectable only in stratified squamous epithelia and not in simple epithelia. The relatively weak and focal staining in tracheal epithelium indicates a low level of PAI-2 antigen present in some simple epithelia. Our findings of low to undetectable levels of PAI-2 in simple epithelia contrast greatly with the strong and consistent signal for both PAI-2 antigen and mRNA in all stratified squamous epithelia examined.

\section{Discussion}

In the present study, we have demonstrated that mouse stratified squamous epithelia (epidermis, tongue, esophagus, oral and vaginal mucosa) constitutively and strongly express the proteinase inhibitor PAI-2. In nearly all 

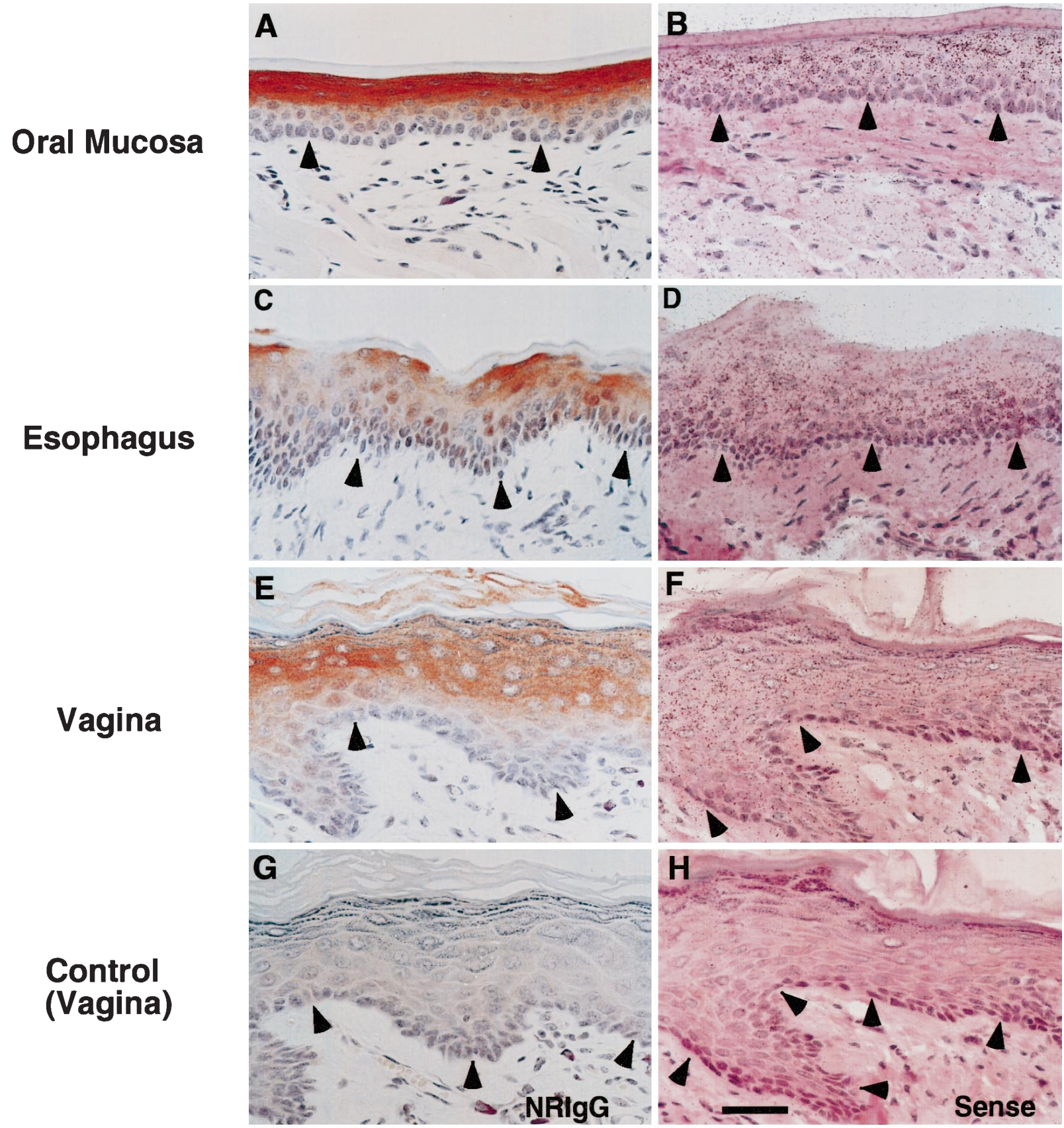

\section{Trachea}
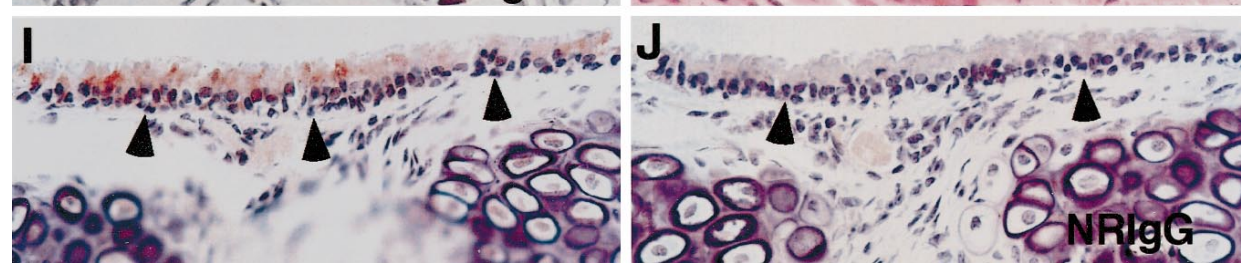

Fig. 6A-J PAI-2 antigen and mRNA are expressed in stratified squamous epithelia. PAI-2 antigen $(\mathbf{A}, \mathbf{C}, \mathbf{E})$ and mRNA $(\mathbf{B}, \mathbf{D}, \mathbf{F})$ were localized in mouse palatal oral mucosa $(\mathbf{A}, \mathbf{B})$, esophagus $(\mathbf{C}$, D) or vagina $(\mathbf{E}, \mathbf{F})$. Control experiments were performed using normal rabbit IgG $(\mathbf{G} \mathrm{NRIgG})$ and $\left[{ }^{35} \mathrm{~S}\right]$-labeled sense probe for PAI-2 mRNA (H). PAI-2 antigen was weakly detectable in the simple epithelium of adult mouse trachea (I) as compared to control staining with NRIgG $(\mathbf{J})$. Arrowheads mark the basement membrane. In all stratified squamous epithelia, expression of PAI2 antigen and mRNA was concentrated in the differentiated, suprabasal epithelial cells. Focal regions of tracheal mucosa showed weak staining for PAI-2 antigen. Bar $40 \mu \mathrm{m}$ cases, both antigen and mRNA for PAI-2 are concentrated in the suprabasal, i.e., differentiating cells of these multi-layered epithelia. In contrast, simple epithelia such as trachea and intestine, which comprise only a single layer of cells residing on a basement membrane, synthesize little or no PAI-2. We suggest that expression of PAI-2 in the differentiating cells of stratified squamous epithelia indicates a connection of this inhibitor to the particular properties of terminal differentiation and death in stratified squamous epithelia. 
One marker of differentiation consistently and uniquely expressed by stratified squamous epithelia is transglutaminase 1 (Parenteau et al. 1986; Reibel et al. 1989; Pfundt et al. 1996). This enzyme cross-links proteins to generate the cornified envelope, which is a unique terminal differentiation product of stratified squamous epithelia, crucial for their barrier function (Green 1977; Rice and Green 1979, Hohl and Roop 1993; Fujimoto et al. 1997). PAI-2 contains a putative transglutaminase substrate motif and has been shown to be incorporated into the cornified envelope of the epidermal keratinocyte (Jensen et al. 1995, Robinson et al. 1997). There is evidence from other investigators that PAI-2 cross-linked to trophoblast membranes via the action of endogenous transglutaminase retains inhibitory activity (Jensen et al. 1993). Late in terminal differentiation, when the cornified envelope is forming, the keratinocyte also proteolytically degrades its organelles via the action of cellular proteinases. For example, Green (1977) provided evidence that, at least in cultured human keratinocytes, plasminogen is involved specifically in nuclear disintegration. Hence we speculate that transglutaminase-mediated cross-linking of PAI-2 may concentrate the inhibitor along the cornified envelope in order to protect this vital structure from the degradative action of cellular proteinases.

A second, perhaps related possibility is that PAI-2 may protect the squamous differentiating cells from dying prematurely. In several cell lines, PAI-2 has been shown to exert a cytoprotective effect against the induction of programmed cell death (Kumar and Baglioni 1991, Dickinson et al. 1995, 1998). Recent studies of mutagenized PAI-2 have shown that a particular interhelical domain is required for this cytoprotective effect; the same domain has previously been implicated in transglutaminase-catalyzed cross-linking of PAI-2 (Jensen et al. 1993, 1994; Dickinson et al. 1998). Simple as well as stratified epithelial cells undergo a highly specialized form of programmed cell death (Fesus et al. 1991; Gavrieli et al. 1992; Hall et al. 1994; Polakowska and Haake 1994; Tamada et al. 1994; Metcalfe and Streuli 1997), but regulatory mechanisms involved in the initiation, commitment, and execution of the death pathway may not be identical among all types of epithelia. One potentially relevant difference imposed by the structural organization of epithelia concerns their attachment to the basement membrane, which has been shown in numerous epithelial cell types to be an important survival signal. Epithelial cells denied contact with their extracellular matrix undergo rapid programmed cell death (Frisch and Francis 1994; Pullan et al. 1996; Metcalfe and Streuli 1997; Rodeck et al. 1997). While simple epithelial cells remain in contact with the basement membrane throughout differentiation, stratified squamous epithelial cells undergo most of their differentiation program after they have detached from the basement membrane. To accomplish their many stages of differentiation and generate a fully functional cornified envelope, stratified squamous epithelial cells must remain viable and metabolically active for long periods of time after they have detached from the basement membrane. Hence we speculate that
PAI-2 may be involved in protecting stratified squamous epithelial cells, which have already lost their attachment to the extracellular matrix and thus are vulnerable, from undergoing too rapidly the execution stages of programmed cell death.

Both of the above hypotheses regarding the role of PAI-2 in stratified squamous epithelia imply an intracellular site of action. For PAI-2 to be incorporated into the cornified envelope, it would have to be located inside the cell, since the cornified envelope is organized on the intracellular face of the plasma membrane. In the studies in which PAI-2 was overexpressed in cell lines, protection from programmed cell death correlated with intracellular PAI-2 (Dickinson et al. 1995,1998). In all stratified squamous epithelia, our immunohistochemical staining pattern for PAI-2 suggests a cytoplasmic distribution. The great majority of PAI-2 in stratified squamous epithelia has an apparent molecular weight of 43 $\mathrm{kDa}$, consistent with the non-glycosylated form, which has been shown to be cell-associated in many cells, including monocytes and cultured human keratinocytes (Wohlwend et al. 1987a, b; Wang and Jensen 1998). Further analyses revealed that most of the $43 \mathrm{kDa}$ PAI-2 is active. In epidermal extracts we also routinely detected several minor species of PAI-2 with apparent molecular weights in the range 33-39 $\mathrm{kDa}$. These species may be related to an approximately $33 \mathrm{kDa}$ form of PAI-2 found by others (Jensen et al. 1994b) in extracts of myeloleukemia cells; it has been postulated that this form is generated in the cytosol and is a biochemical marker for apoptosis. Since PAI-2 is a member of the large family of serpins, most of which are found in the circulation, the postulation of an intracellular role was initially suprising. However, PAI-2 is an ovalbumin-type serpin (ov-serpin), with structural and sequence homology to serpins such as skin-derived anti-leukoproteinase (SKALP), proteinase inhibitor 6, maspin, squamous cell carcinoma antigen (SCCA), and the viral serpin crmA (Kruithof et al. 1995). Ov-serpins lack a classical signal sequence and are therefore expressed mainly in the cytosol; in some cases, secretion is facilitated by glycosylation of the inhibitor molecule. Recent studies have localized SKALP, proteinase inhibitor 6, and SCCA to the more differentiated keratinocytes of various types of stratified squamous epithelia (Pfundt et al. 1996; Scott et al. 1996; Schick et al. 1997). In the case of proteinase inhibitor 6, expression was found to be exclusively intracellular, suggesting yet unknown intracellular function(s) of this serpin. Furthermore, as an inhibitor of the intracellular caspase interleukin-1 $\beta$-converting enzyme (ICE), the viral serpin crmA is the first serpin shown to have a defined intracellular target (Komiyama et al. 1996).

Although several lines of evidence point to an intracellular role for PAI-2, we recognize that an alternative, or additional, extracellular role for PAI-2 involves inhibition of UPA or tPA. Both of these plasminogen activators are present in normal mouse epidermis (Jensen and Lavker 1996). Although their epidermal functions remain undefined, we have previously presented evidence that uPA may promote epidermal proliferation (Jensen 
and Lavker 1996). Interestingly, of all the murine stratified squamous epithelia that we examined, adult epidermis of the 'thin' phenotype was the only one in which PAI-2 was found in the basal (i.e., proliferative) layer. This may suggest that, at least under certain conditions, PAI-2 may serve additional functions in basal keratinocytes, e.g., regulation of uPA activity.

Finally, it is possible that PAI-2 may provide a protective mechanism against microbial infection through stratified squamous epithelia. Although intact epithelia constitute a formidable barrier against microbial invasion, breaks within tissues can allow entry of foreign organisms. Several invasive bacteria express endogenous plasminogen activators and bind plasminogen, which they may use to penetrate the extracellular matrix (Boyle and Lottenberg 1997; Korhonen et al. 1997). Perhaps disruption of the stratified squamous epithelium, with the resulting death of keratinocytes, releases their large store of intracellular PAI-2 into the extracellular space, there to inhibit any bacterial-mediated plasminogen activation and thus limit the invasive capacity of the infectious agent.

In sum, we believe that the selective presence of PAI-2 in the differentiated cells of stratified squamous epithelia suggests several possible roles related to the protective barrier functions of this class of epithelia. Future investigations are required to determine the nature and the target of PAI-2 actions.

Acknowledgements This work was supported by a research fellowship from the Dermatology Foundation and Merck \& Co. to B.C.R. and grants from the National Institutes of Health to P.J.J. (RO1 AR42998), R.M.L. (RO1 EY06769), and D.G. (RO1 HL49184). The authors are very grateful for the outstanding histotechnical expertise of Ms Dorothy Campbell.

\section{References}

Andreasen PA, Georg B, Lund LR, Riccio A, Stacey SN (1990) Plasminogen activator inhibitors: hormonally regulated serpins. Mol Cell Endocrinol 68:1-19

Andreasen PA, Kjoller L, Christensen L, Duffy MJ (1997) The urokinase-type plasminogen activator system in cancer metastasis: a review. Int J Cancer 72:1-22

Ashkenas J, Werb Z (1996) Proteolysis and the biochemistry of life-or-death decisions. J Exp Med 183:1947-1951

Belin D, Wohlwend A, Schleuning W-D, Kruithof EKO, Vassalli J-D (1989) Facultative polypeptide translocation allows a single mRNA to encode the secreted and cytosolic forms of plasminogen activator inhibitor 2. EMBO J 8:3287-3294

Boyle MDP, Lottenberg R (1997) Plasminogen activation by invasive human pathogens. Thromb Haemost 77:1-10

Carmeliet P, Collen D (1995) Gene targeting and gene transfer studies of the biological role of the plasminogen/plasmin system. Thromb Haemost 74:429-436

Danø K, Andreasen PA, Grøndahl-Hansen J, Kristensen P, Nielsen LS, Skriver L (1985) Plasminogen activators, tissue degradation, and cancer. Adv Cancer Res 44:139-266

Dickinson JL, Bates EJ, Ferrante A, Antalis TM (1995) Plasminogen activator inhibitor type 2 inhibits tumor necrosis factor $\alpha$ induced apoptosis. J Biol Chem 270:27894-27904

Dickinson JL, Norris BL, Jensen PH, Antalis TM (1998) The C-D interhelical domain of the serpin plasminogen activator inhibitor-type 2 is required for protection from TNF- $\alpha$-induced apoptosis. Cell Death Differ 5:163-171
Eckert RL, Rorke EA (1989) Molecular biology of keratinocyte differentiation. Environ Health Perspect 80:109-116

Fesus L, Davies PJA, Piacentini M (1991) Apotposis: molecular mechanism in programmed cell death. Eur J Cell Biol 56: $170-177$

Frisch SM, Francis H (1994) Disruption of epithelial cell-matrix interactions induces apoptosis. J Cell Biol 124:619-626

Fujimoto W, Nakanishi G, Arata J, Jetten AM (1997) Differential expression of human cornifin $a$ and $b$ in squamous differentiating epithelial tissues and skin lesions. J Invest Dermatol 108: 200-204

Gavrieli Y, Sherman Y, Ben-Sasson SA (1992) Identification of programmed cell death in situ via specific labeling of nuclear DNA fragmentation. J Cell Biol 119:493-501

Green H (1977) Terminal differentiation of cultured human epidermal cells. Cell 11:405-416

Green H (1980) The keratinocyte as differentiated cell type. Harvey $\operatorname{Lec} 74: 101-139$

Hall PA, Coates PJ, Ansari B, Hopwood D (1994) Regulation of cell number in the mammalian gastrointestinal tract - the importance of apoptosis. J Cell Sci 107:3569-3577

Hibino T, Izaki S, Ohkuma M, Kon S, Thorsen S, Astedt B (1988) Epidermal plasminogen activator inhibitor (PAI) is immunologically identical to placental-type PAI-2. FEBS Lett 231:202-206

Hohl D, Roop D (1993) Loricrin. In: Darmon M, Blumenberg M (eds) Molecular biology of the skin: the keratinocyte. Academic Press, San Diego, pp 151-179

Jensen PH, Lorand L, Ebbesen P, Glieman J (1993) Type-2 plasminogen-activator inhibitor is a substrate for trophoblast transglutaminase and factor XIIIa. Transglutaminase-catalyzed cross-linking to cellular and extracellular structures. Eur J Biochem 214:141-146

Jensen PH, Schuler E, Woodrow G, Richardson M, Goss N, Hojrup P, Peterson TE, Rasmussen LK (1994a) A unique interhelical insertion in plasminogen activator inhibitor 2 contains three glutamines, Gln83 Gln84 Gln86, essential for transglutaminase-mediated cross-linking. J Biol Chem 269:15394-15398

Jensen PH, Cressey LI, Gjertsen BT, Madsen P, Mellgren G, Hokland P, Gliemann J, Døskeland SO, Lanotte M, Vintermyr OK (1994b) Cleaved intracellular plasminogen activator inhibitor 2 in human myeloleukemia cells is a marker of apoptosis. Br J Cancer 70:834-840

Jensen PJ, Lavker RM (1996) Modulation of the plasminogen activator cascade during enhanced epidermal proliferation in vivo. Cell Growth Differ 7:1793-1804

Jensen PJ, Wu Q, Janowitz P, Ando Y, Schechter NM (1995) Plasminogen activator inhibitor type 2: an intracellular keratinocyte differentiation product that is incorporated into the cornified envelope. Exp Cell Res 217:65-71

Kawata Y, Mimuro J, Kaneko M, Shimada K, Sakata Y (1996) Expression of plasminogen activator inhibitor 2 in the adult and embryonic mouse tissues. Thromb Haemost 76:569-576

Keeton M, Eguchi Y, Sawdey M, Ahn C, Loskutoff D (1993) Cellular localization of type 1 plasminogen activator inhibitor messenger RNA and protein in murine renal tissue. Am J Pathol 142:59-70

Komiyama T, Long TQ, Salvesen GS (1996) Inhibition of cysteine and serine proteinases by the cowpox virus serpin crmA. Adv Exp Med Biol 389:173-176

Korhonen TK, Lähteenmäki K, Kukkonen M, Pouttu R, Hynönen U, Savolainen K, Westerlund-Wikström B, Virkola R (1997) Plasminogen receptors. Turning Salmonella and Escherichia coli into proteolytic organisms. Adv Exp Med Biol 412:185-192

Kruithof EKO, Bakers MS, Bunn CL (1995) Biological and clinical aspects of plasminogen activator inhibitor type 2. Blood 86:4007-4024

Kumar S, Baglioni C (1991) Protection from tumor necrosis factor-mediated cytolysis by overexpression of plasminogen activator inhibitor type-2. J Biol Chem 266:20960-20964

Lyons-Giordano B, Loskutoff D, Chen CS, Lazarus GS, Keeton M, Jensen PJ (1994) Expression of plasminogen activator inhibitor type 2 in normal and psoriatic epidermis. Histochemistry 101:105-112 
Mars WM, Zarnegar R, Michalopoulos GK (1993) Activation of hepatocyte growth factor by the plasminogen activators uPA and tPA. Am J Pathol 143:949-958

Metcalfe A, Streuli C (1997) Epithelial apoptosis. Bioessays 19: $711-720$

Mikus P, Urano T, Liljeström P, Ny T (1993) Plasminogen-activator inhibitor type 2 (PAI-2) is a spontaneously polymerising serpin. Biochemical characterisation of the recombinant intracellular and extracellular forms. Eur J Biochem 218:1071-1082

Naldini T, Tamagone L, Vigna E, Sachs M, Hartmann G, Birchmeier W, Daikuhara Y, Tsubouchi H, Blasi F, Comoglio PM (1992) Extracellular proteolytic cleavage by urokinase is required for activation of hepatocyte growth factor/scatter factor. EMBO J 11:4825-4833

Parenteau NL, Pilato A, Rice RH (1986) Induction of keratinocyte type-I transglutaminase in epithelial cells of the rat. Differentiation 33:130-141

Pfundt R, Ruissen F van, Vlijmen-Willems IMJJ van, Alkemade HAC, Zeeuwen PLJM, Lap PH, Dijkman H, Fransen J, Croes H, Erp PEJ van, Schalkwijk J (1996) Constitutive and inducible expression of SKALP/elafin provides anti-elastase defense in human epithelia. J Clin Invest 98:1389-1399

Polakowska RR, Haake AR (1994) Apoptosis: the skin from a new perspective. Cell Death Differ 1:19-31

Pullan S, Wilson J, Edwards GM, Goberdhan N, Tilly J, Hickman JA, Dive C, Streuli CH (1996) Requirement of basement membrane for the suppression of programmed cell death in mammary epithelium. J Cell Sci 109:631-642

Quigley JP, Gold LI, Schwimmer R, Sullivan LM (1987) Limited cleavage of cellular fibronectin by plasminogen activator purified from transformed cells. Proc Natl Acad Sci USA 84:2776-2780

Reibel J, Clausen H, Dale BA, Thacher SM (1989) Immunohistochemical analysis of stratum corneum components in oral squamous epithelia. Differentiation 41:237-244

Resing KA, Al-Alawi N, Blomquist C, Fleckman P, Dale BA (1993) Independent regulation of two cytoplasmic processing stages of the intermediate filament-associated protein filaggrin and role of $\mathrm{Ca}^{2+}$ in the second stage. J Biol Chem 268:25139-25145

Rice RH, Green H (1979) Presence in human epidermal cells of a soluble protein precursor of the cross-linked envelope: activation of the cross-linking by calcium ions. Cell 18:681-694

Robinson NA, Lapic S, Welter JF, Eckert RL (1997) S100A11, S100A10, annexin I, desmosomal proteins, small proline-rich proteins, plasminogen activator inhibitor-2, and involucrin are components of the cornified envelope in cultured human epidermal keratinocytes. J Biol Chem 272:12035-12046

Rodeck U, Jost M, DuHadaway J, Kari C, Jensen PJ, Risse B, Ewert DL (1997) Regulation of Bcl- $\mathrm{x}_{\mathrm{L}}$ expression in human keratinocytes by cell-substratum adhesion and the epidermal growth factor receptor. Proc Natl Acad Sci USA 94: 5067-5072

Rømer J, Bugge TH, Pyke C, Lund LR, Flick MJ, Degen JL, Danø K (1996) Impaired wound healing in mice with a disrupted plasminogen gene. Nat Med 2:287-292

Schick C, Kamachi Y, Bartuski AJ, Cataltepe S, Schechter NM, Pemberton PA, Silverman GA (1997) Squamous cell carcinoma antigen 2 is a novel serpin that inhibits the chymotrypsinlike proteinases cathepsin $\mathrm{G}$ and mast cell chymase. J Biol Chem 272:1849-1855

Scott FL, Coughlin PB, Bird C, Cerruti L, Hayman JA, Bird P (1996) Proteinase inhibitor 6 cannot be secreted, which suggests it is a new type of cellular serpin. J Biol Chem 271: $1605-1612$

Tamada Y, Takama H, Kitamura T, Yokochi K, Nitta Y, Ikeya T, Matsumoto Y (1994) Identification of programmed cell death in normal human skin tissues by using specific labelling of fragmented DNA. Br J Dermatol 131:521-524

Tsirka SE, Rogove AD, Bugge TH, Degen JL, Strickland S (1997) An extracellular proteolytic cascade promotes neuronal degeneration in the mouse hippocampus. J Neurosci 17:543552

Wang Y, Jensen PJ (1998) Regulation of the level and glycosylation state of plasminogen activator inhibitor type 2 during keratinocyte differentiation. Differentiation 63:93-99

Wohlwend A, Belin D, Vassalli J-D (1987a) Plasminogen activator-specific inhibitors in mouse macrophages: in vivo and in vitro modulation of their synthesis and secretion. J Immunol 139:1278-1284

Wohlwend A, Belin D, Vassalli J-D (1987b) Plasminogen activator-specific inhibitors produced by human monocytes/macrophages. J Exp Med 165:320-339

Ye RD, Wun RC, Sadler JE (1988) Mammalian protein secretion without signal peptide removal. Biosynthesis of plasminogen activator inhibitor-2 in U-937 cells. J Biol Chem 263:4869-4875 